\title{
Learner Agency in China's Program for Interdisciplinary English Talents: A Sociocultural Perspective
}

\author{
Fengju Dai ${ }^{1} \&$ Xiao Lin $^{2}$ \\ ${ }^{1}$ College of International Studies, Southwest University, Chongqing, China \\ ${ }^{2}$ School of International Studies, Zhejiang University, Hangzhou, China \\ Correspondence: Xiao Lin, School of International Studies, Zhejiang University, Hangzhou, China. E-mail: \\ xiaolinzju@163.com
}

Received: August 2, 2021

Accepted: September 9, 2021

Online Published: September 19, 2021

doi:10.5539/ijel.v11n6p1

URL: https://doi.org/10.5539/ijel.v11n6p1

\begin{abstract}
Aiming to develop a sociocultural understanding of learner agency as defined by Ahearn (2001), this study asks the questions: How do English majors under the Program for Interdisciplinary English Talents in Chinese universities with international or regional orientations experience their English learning and exert learner agency differently? Which factors influence learners' agentive activities and what differences exist in the influencing strength of those factors? Interview data were collected from 14 student participants from two representative universities in the eastern part of China. Analyzing the data using the framework proposed by Dang and Marginson (2013) revealed that learners' agentive activities are mediated by the sociocultural context, in which the global, national and local factors exert great influences and their influencing strength varies. Among all the factors, the influence of the microgenetic domain, to be specific, the institutional context is the greatest. Implications and suggestions are provided based on the results.
\end{abstract}

Keywords: learner agency, sociocultural theory, the program for interdisciplinary English talents, China

\section{Introduction}

\subsection{The Problem}

At present, the research focus in the language policy and planning (thereafter LPP) field is the interrelation between the macro level and the micro level, that is, the macro policies and micro practices and individual agency. To address this, the recent developments within linguistics that understand the role of language and other sociocultural artefacts in the mediation of human activity and social practice from the Vygotskian sociocultural perspective have been increasingly adopted (Cross, 2009). With the development of globalization, the global level is also an important element in the sociocultural context. In the exploration of policy-practice interrelationship in the education field, agency has been seen as a new issue and context being given prominence in LPP (Liddicoat \& Taylor-Leech, 2021). Particularly, learner agency in LPP enactment and implementation at the micro-level has received increasing attention in the literature (Brown, 2015; Phan \& Hamid, 2017; Manyukhina \& Wyse, 2019; Finardi \& Guimarães, 2021; Vennela \& Kandharaja, 2021). Nevertheless, in the exploration of learner agency, the empirical research of the learners' agentive activities at the micro-level and factors that have an impact on learner agency is still scarce. The examination of those is not only a symbol of the further development of LPP scholarship but also a requirement of language activities in increasingly complex sociocultural contexts.

Since the implementation of the reform and opening-up policy, the labor market has set higher requirements for English majors in China. The linguistic-oriented Syllabus for the Bachelor of Arts (thereafter BA) program for English majors in China could not meet these requirements (Dai, 2008). Thus, there was an urgent need to reform the program for foreign language talents and to cultivate interdisciplinary talents. On the basis of extensive investigations, in 1998, a document named Several Opinions about the Reform of Foreign Language Education put forward the Program for Interdisciplinary English Talents (thereafter the program) in which the expressed opinion is that foreign language education should be integrated with other majors, with types including foreign language + other majors, other majors + foreign language, foreign language + professional courses, etc. In 2000, the new syllabus, English Teaching Syllabus for Tertiary English Majors, was issued, and 
the program was officially implemented in BA program for English majors.

In examining the literature about the program, a predominance of top-down perspective is apparent. Most researchers investigated its merits and demerits, and its rationality and operability (Zhong, 2006; Yang, 2007; Li $\& \mathrm{Xu}, 2006$; Dai, 2008). In recent years, some researchers have begun to focus on the implementation process of this policy in one specific context (Hu, 2010; Zhang, 2012; Liu \& Li, 2014). It could be argued that, in the study of the program, the bottom-up, insider perspectives and practices of the micro-level groups have not been given due importance to. Moreover, Chinese universities are divided into internationally-oriented and originally-oriented, but comparative empirical researches between universities with different orientations are lacking. Also, in 2018, the National Standards of Teaching Quality for Undergraduate Foreign Language and Literature Majors, which is a guidance document for the cultivation of English majors in China in the coming years, was promulgated. Such researches can provide great implications to the implementation of this new language policy.

Seeking to address this situation, this study focuses on learner agency and the factors mediating learners' agentive activities in the hope of enriching the research field about the program and contributing to the study of learner agency in the LPP.

\subsection{Literature Review}

\subsubsection{Theoretical Framework}

Vygotsky (1981a) regarded humans as subjects of both sociocultural evolution and natural evolution. The core of this argument is the dialectic relationship between humans and the sociocultural contexts. Two notions have been adopted to conceptualize this dialectic, that is, mediational artefacts and the genetic method.

Vygotsky (1981a) emphasized that artefacts play a central role in the sociocultural contexts and in human development. He divided artefacts into two types on the basis of different orientations, that is, the physical "tools" and psychological "signs", the former is externally oriented, helping humans to master nature by influencing the relation with nature and by conducting and changing behaviors, whereas the latter is internally oriented, aiming at controlling their behavior by using extrinsic stimuli (Vygotsky, 1978). In LPP research field, policy is regarded as a sociocultural artefact that mediates human activities both in macro and micro contexts, presenting the function of policy as a mediatory tool (Cross, 2009). The artefacts change with the development of human society, behavior thus can only be seen as the history of behavior (Vygotsky, 1981a). Vygotsky (1981b) then identified four general fundamental genetic stages through which behavioral development passes. He named it as "genetic method", which provides "the basic foundation for a broader meta-theoretical framework through which to explicate the interrelationship between concrete, practical activity and the broader cultural-historical domain from which that activity has emerged" (Cross, 2009, p. 27).

However, with the acceleration of globalization, global elements have become increasingly essential in theorization and research. Once developed to incorporate global phenomena into the genetic method and the notion of mediating artefacts, Vygotsky's ideas have much to offer to the analysis of globally affected educational practices, which have been viewed as "glonacal" activities shaped simultaneously in global, national and local spheres (Dang \& Marginson, 2013).

Based on these insights, Dang and Marginson (2013) put forward a conceptual approach which combines the spatial insights of the "glonacal" agency heuristic promoted by Marginson and Rhoades (2002) with the socio-historical relational understandings enabled by the "genetic method" (Vygotsky, 1981b). The latter works as the bond that has linked and penetrated the four domains of the former. In "genetic method", four domains are included: phylogenetic domain (the natural evolution humans undergo), cultural-historical domain (extended to be cultural-historical-economic-political domain by Dang and Marginson (2013)) (the social contexts of human activities, i.e., the social, cultural, and historical bases for human development), ontogenetic domain (the lifespan an individual goes through) and microgenetic domain (the momentary instances of concrete, practical activities that subjects are engaged in across the world, and the microgenetic sites in which subjects exist). In "glonacal" agency heuristic, three dimensions are included: global, national and local. It emphasizes the intersection, interaction and mutual determination of global, national and local dimensions and forces in comparative higher education research.

In this framework (Figure 1), the ellipse is used to highlight the nestedness of the dimensions as one unified whole at any specific point in time. The effect of the global level is more salient in phylogenetic domain and cultural-historical domain (cultural-historical-economic-political domain), and the effect of the local level is more salient in ontogenetic domain and microgenetic domain. Moreover, in all these genetic domains, there are 
traces of all these three levels.

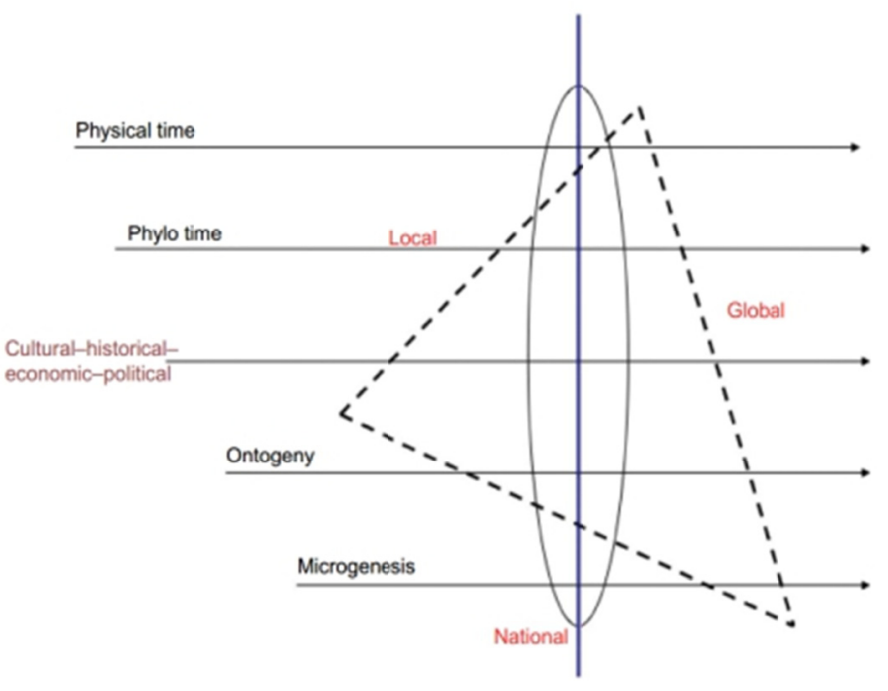

Figure 1. Dang and Marginson's framework

Source: Dang \& Marginson, 2013, p. 150.

Adopting this theoretical framework, Dang and Marginson (2013) explored the learning of a cohort of Vietnamese pre-service teachers during their practicum through interview and they concluded that "global flows, media and artifacts, which are used extensively by these teachers, articulate with national and local practices and conventions in innovative ways" (Dang \& Marginson, 2013, p. 143). Teachers' ontogenetic experiences have also had great influence on their teaching practice, that is, their microgentic activities. To examine how contemporary globalization encourages using English as a medium of instruction in teacher education in non-native English-speaking countries, some studies (e.g., Dang, 2012; Dang, Nguyen, \& Le, 2013) adopted interviews and classroom observations to examine the views and practice of Vietnamese pre-service teachers and showed that global influence on teaching practices is mediated by a number of elements, including social and community pressures, trends of the internationalization of education, and the availability of teaching resources. The above three researches employing this framework explored the mediational function of elements at one or more levels with qualitative analysis method. What lacks is the exploration of the influencing strength of factors by quantitatively presenting data results.

\subsubsection{Learner Agency in Language Policy}

Agency, "the socioculturally mediated capacity to act" (Ahearn, 2001, p. 112), refers to one's ability to act, to make choices, and to reflect on their actions in relation to themselves and the social environment (Ahearn, 2001; Lantolf \& Pavlenko, 2001). It is not equivalent to "free will", which has only given lip service to "the social nature of agency and the pervasive influence of culture on human intentions, beliefs, and actions" (Ahearn, 2001, p. 114). Meanwhile, it does not mean "resistance", because "oppositional agency is only one of many forms of agency" (ibid, p. 114). Traditionally, researches about actors have been addressed in rather general terms and actors' agency has been analyzed in an aggregated way. Individuals, as an actor in LPP, have received little attention (Zhao \& Baldauf, 2012). However, the individual agency exercised by local actors, who ostensibly constitute "the most crucial level of LPP" (Hamid \& Baldauf, 2014), has an impact on a policy, or might even "compromise the impact of a national language policy" (Baldauf, 2012, p. 240). The emphasis on actors at the micro or local level has brought studies of LPP to a new territory (Fenton-Smith \& Gurney, 2016). Consistent with Ahearn's definition, in LPP research field, the subject, who is constrained or facilitated by the policies, is not a completely free agent in the microgenetic domain (Cross, 2009).

Learner agency has long been a focus in the school context in the LPP research field. Brown (2015) adopted an anthropological methodology to reanalyze the study conducted by Siekmann and Charles (2011) from poststructuralist and sociocultural perspectives. He claimed that a sociocultural perspective can provide a more concrete conceptualization of how learners' agentive activities operate interactively with teacher agency, and qualitative data on learner agency can be drawn upon in micro policy-making and planning. Phan and Hamid 
(2017) examined how learner autonomy has been understood by adopting a Vygotskian activity theory framework suggested by Cross (2009) from the perspective of teacher agency in a Vietnam university. Finardi and Guimarães (2021) viewed learners as one of the local agents and explored their opinions and level of satisfaction through questionnaires. Vennela and Kandharaja (2021) investigated the language attitudes of university learners in India towards English and its use. They examined how the learners exert their agency as they negotiate with, respond to, and evaluate their language ecology by employing qualitative research. Specifically, Manyukhina and Wyse (2019) highlighted four levels of sociocultural elements that impacted learner agency theoretically, i.e., contextual, intra-personal, interpersonal and temporal levels. The previous studies have shed light on the essential role learner agency plays in the process of LPP implementation and highlighted the impact of contextual factors. However, the accurate presentation of the influencing strength of elements at various levels is lacking. Researches in related fields, such as Psychology (e.g. Wang, She, \& Song, 2014), have confirmed the feasibility of the quantitative presentation of qualitative data, which can accurately reflect the influencing strength of factors. Such an approach hasn't been adopted to explore learner agency yet.

In this case, the study will specifically seek the answers to the following two research questions:

Research question 1: How do English majors under the program in Chinese universities with international or regional orientations experience their English learning and exert learner agency differently?

Research question 2: Which factors influence learners' agentive activities and what differences exist in the influencing strength of those factors?

The aim of the present study is, through quantitatively presented qualitative analysis, to explore the factors that have an effect on learners' agentive activities and their influencing strength under the program in different research settings by taking Dang and Marginson's framework as its basis.

\section{The Study}

\subsection{Setting}

The study was conducted in two universities. U-A is a regionally-oriented, provincial university of science and engineering, located in the eastern part of China. The BA program for English majors of this university was established in 2002. In 2008, on the basis of the program, this university's cultivation program for English Majors was developed. The type of the program in this university was taking direction courses in the third year of university, in which three directions were included: Translation, Economy and Trade.

U-B is an internationally-oriented comprehensive university directly under the Ministry of Education, located in the same city as U-A. There were three types of interdisciplinary programs in U-B: second degree, minor credential, taking direction courses or minor field courses. English majors can choose one of them in their second year. Second degree means that students should finish all the courses required by the second-degree qualification policy established by the relevant departments. Minor credential means that students who chose this type should finish all the courses required by the minor credential policy established by the relevant departments. The credits requirement of minor credential was lower than that of the second degree. Taking direction courses or minor field courses means that students took courses provided by other departments or the Foreign Language Department without intention to obtain a second degree or a minor credential.

\subsection{Methods}

A multi-site case study was employed in this study. Survey and focused interview were employed to collect data. The interview data collection incorporated three of the four Vygotskian genetic domains: cultural-historical, ontogenetic and microgenetic domains. To be in consistence with the scope of this study, the phylogenetic domain is not included.

The data were collected through the following steps:

Firstly, a total number of 141 questionnaires were distributed in both universities to collect the information about the activities that learners conducted during their college life under the program and the institutional provisions, including the following aspects: their choices of the types of the interdisciplinary program, their language learning activities, the activities that are of help to their future in their mind. All the questionnaires are valid.

Secondly, seven learners who were willing to share their stories from each university were invited to participate in the interview. The interview questions include learners' English learning experience, the reasons for learners' choosing English major; learners' opinions about the program and the cultivation program of their university. An additional number of detailed questions were asked based on various experiences of the learners. The interviews were conducted twice in both universities. In U-A, the first one was conducted in teachers' office on $10^{\text {th }}$, June 
2016 through group interview, which lasted for about 1.5 hours. The second one was conducted on $17^{\text {th }}$, Nov 2016 through individual interview in teachers' office. In U-B, the first one was conducted on $30^{\text {th }}$, April 2017 , and the second one occurred on $6^{\text {th }}$, May 2017. Both were conducted in the library of U-B by individual interview. The purposes of the second interview were to confirm information and ask for clarification. Moreover, there were some repeated questions, which were employed to enhance the validity and reliability. The interviews were recorded and the responses were transcribed verbatim. The total number of the Chinese characters of the transcripts is 173,009 .

Supported by the research software NVivo 11.0, the interview data were coded. In the data coding process, according to the number of times a factor is mentioned by interviewees, the reference points can be calculated. Based on the number of reference points, the influencing strength is quantitated. The analysis process included the following stages: The interview transcripts were used for initial coding. The first step was to create nodes by gathering statements with a similar emphasis under the same node. The nodes generated in this process were named "spheres". The second step was to distill those spheres, the ones generated in this process being called "subcategories". In the third step, the subcategories were abstracted to produce broader concepts labeled as "categories". Then, the categories, subcategories, and spheres were utilized to analyze the influencing strength according to the number of reference points and to explore the specific content by gaining supports from the interview data. In the last step, the results of the comparative case studies were presented and analyzed.

\subsection{Participants}

The participants of the surveys are learners enrolled in 2013, 91 (12 males and 78 females) in U-A and 50 (15 males and 36 females) in U-B. The total number of interview participants is 14,7 from each university respectively. For the principle of anonymity, they are represented by University plus a serial number (see Table 1 for details).

Table 1. Interview participants' background information

\begin{tabular}{lllllllc}
\hline Number & Gender & Origin (province) & University & Number & Gender & Origin (province) & University \\
\hline U-A1 & Male & Guizhou & U-A & U-B1 & Female & Shandong & U-B \\
U-A2 & Male & Zhejiang & U-A & U-B2 & Female & Shanxi & U-B \\
U-A3 & Female & Zhejiang & U-A & U-B3 & Female & Zhejiang & U-B \\
U-A4 & Female & Zhejiang & U-A & U-B4 & Female & Shanxi & U-B \\
U-A5 & Female & Shanxi & U-A & U-B5 & Male & Shanxi & U-B \\
U-A6 & Female & Zhejiang & U-A & U-B6 & Male & Shanxi & U-B \\
U-A7 & Female & Zhejiang & U-A & U-B7 & Female & Shanxi & U-B \\
\hline
\end{tabular}

\section{Research Results and Discussion}

\subsection{Data Results}

\subsubsection{Learners' Agentive Activities}

The data reveal that the learners in both universities conducted a series of activities to fulfill their own needs. The activities recognized as agentive include the following: (1) Learners' choices of the types of the interdisciplinary program. Survey statistics show that, in U-A, all learners choose to take direction courses; and in U-B, $16 \%$ of the learners choose to gain a second degree, $44 \%$ choose to gain a minor degree, $24 \%$ choose to attend courses from other majors and $4 \%$ choose to take direction courses. (2) Working as a trainee. This is an activity that more than half of the learners in U-A conducted. Learners in U-B rarely mention this activity. (3) Gaining qualification certificates by taking examinations. Compared with U-B, more participants in U-A take part in examinations to qualify as being a teacher, a translator, etc. (4) Learning activities. About $80 \%$ of learners in U-A try to improve their language abilities through various ways, such as taking language training courses, reading English books, practicing listening and speaking by themselves, etc. However, learners in U-B pay more attention to activities that are not directly related to English language learning, such as gaining knowledge about other majors or devoting their time to those fields they are interested in, and improving their mathematic ability, etc.

\subsubsection{Influencing Factors of Learner Agency in the Program}

After the data coding, 3 categories, 7 subcategories, and 20 spheres that have an impact on learners' agentive activities are obtained in total. The 3 categories, consistent with the three domains of Dang and Marginson's framework, include: (a) Cultural-historical domain (about the influence of various aspects at different levels, 
including economy, history, policy, culture, etc.); (b) Ontogenetic domain (about the individual, including individual experience, ability, interest, etc.); (c) Microgenetic domain (about the institutional context in which learners live and study, including the institutional policies, courses, teachers, peers, etc.). In the remaining part of this section, the results of our comparative case study analysis are presented in the light of the influencing strength of each category, which is represented by the numerical reference points put in the parenthesis, for example, the "global factors (2)" represents the fact that the number of reference points of global factors in this study is 2 . The larger the number, the stronger the influence.

\subsubsection{Cultural-Historical Domain}

Context, the natural or social context, exerts a great impact on people's lives. What we confront is what elements in this context are at work and what differences and similarities exist when the immediate settings vary. In this study, in the cultural-historical domain, according to the elements mentioned by the interviewees, three levels of contexts constitute the subcategories: global factors (about the whole world or foreign countries), national factors (about the various aspects of China), and local factors (associated with the local city where the institutions are located in). The spheres under each subcategory and the influencing strength of the subcategories and spheres are presented in Table 2 in detail:

Table 2. Influencing strength of subcategories and spheres in the cultural-historical domain

\begin{tabular}{llll}
\hline Subcategories & Spheres & Reference points (U-A) & Reference points (U-B) \\
\hline Global factors & & 2 & 8 \\
& English as lingua franca & 1 & 3 \\
& Global hotspots & 1 & 0 \\
& Global cultural factor & 0 & 5 \\
National factors & & 14 & 16 \\
& National labor market & 12 & 12 \\
Local factors & National education policy factor & 2 & 4 \\
& & 17 & 2 \\
& Local economic factor & 11 & 2 \\
& Local cultural factor & 6 & 0 \\
\hline
\end{tabular}

As Table 2 shows, in different settings, the strength of different elements in the general cultural-historical context varies. The horizontal comparative data results of the two universities illuminate clearly that the global factors (2 in U-A and 8 in U-B) have a greater impact on learners in U-B than in U-A. Most interviewees in U-A perceive this level to be too broad to attract their attention. To the specific spheres, English as a lingua franca (1 in U-A and 3 in U-B) used in various fields in the era of globalization is regarded as a factor that affects learners' language study and attitude in both universities though learners in U-B address this point more. Other spheres are diverse: In U-A, only one interviewee mentions that his interest in the global hotspots (1) encourages him to improve his language ability with the opinion that "to follow the latest international information, English ability is essential (U-A5)". In U-B, interviewees stress the effect of the global cultural factor (5), particularly, the cultural artefacts such as books and other entertainment products. As the following quote illustrates:

Literature books, movies, and TV episodes from English-speaking countries influence my language learning a lot. (U-B7)

In order to develop a deep understanding of those global products, this interviewee strives to learn more about foreign culture and to improve her language ability.

The national factors (14 in U-A and 16 in U-B) exert a similar influence on both universities with 2 spheres, i.e., national labor market (12 in both universities) and national education policy ( 2 in U-A and 4 in U-B). Clearly, compared with the national education policy, the national labor market is perceived as a more significant factor in both universities, which impacts their interdisciplinary course choosing, language learning and attitudes towards the program, as expressed in the quotes below:

To adapt ourselves to the labor market, knowledge about other majors and fields is needed. The program provided us with that opportunity. (U-A2)

The rapid development of cross-broader e-commerce makes me pay more attention to trade and e-commerce, gaining knowledge about which may be useful to my future employment. This program provides me with that chance. (U-B3) 
In the above two quotes, the relationship between the program and the labor market is drawn, which is consistent with the purpose of the promulgation of the program. Interviewees perceive that, theoretically, the program can facilitate their future development, because they can be equipped with language skills as well as other interdisciplinary capacities, which indicates that they hold a positive view towards the program itself.

The local factors (17 in U-A and 2 in U-B) and its two spheres, i.e., the local cultural (6 in U-A and 0 in U-B) and economic factors (11 in U-A and 2 in U-B), all are essential elements for learners in U-A. Particularly, learners in U-A mention that with the development of the local economy, more and more international activities held in the local city set a series of language requirements for being a volunteer, which confirms the advantages and popularity of English majors. As the following quotes show:

As our local city develops, there are more and more international activities held here, such as the international summits and exhibitions and so on. In those activities, English majors occupy a dominant position of being a volunteer because there are language requirements. (U-A3)

The local cultural atmosphere, especially the popularity of the English language, urges learners in U-A to improve their language ability in order to be more proficient than others because they are English majors, which is illustrated by the quote below:

When I walk along the street, I find that English is widely used and almost everyone can speak English in this city. I feel so pressured that I think I must work harder to improve my language. (U-A6)

\subsubsection{Ontogenetic Domain}

In the ontogenetic domain, there are 3 subcategories (interest, ability and experience) and 6 spheres: individual interest, situation interest, language ability, mathematical ability, all-round ability, life experience and learning experience.

The influencing strength of the subcategories and the relevant spheres will be mainly presented and analyzed. The quantitative results are shown in Table 3:

Table 3. Influencing strength of subcategories in the ontogenetic domain

\begin{tabular}{llll}
\hline Category & Subcategories & Reference points (U-A) & Reference points (U-B) \\
\hline Ontogenetic domain & & 25 & 45 \\
& Interest & 7 & 27 \\
& Ability & 10 & 9 \\
& Experience & 8 & 9 \\
\hline
\end{tabular}

As Table 3 presents, the comparative result clearly shows that the impact of the ontogenetic domain (25 in U-A and 45 in U-B) is stronger in U-B than that in U-A, which reveals that learners in U-B lay more emphasis on their individual factors than learners in U-A. Concerning subcategories, the most pronounced difference between the two universities is the interest ( 7 in U-A and 27 in U-B). Learners in U-B lay more emphasis on the interest than learners in U-A. When it comes to interest, learners in U-A concern more about future employment. For instance, U-A6 mentions that "I don't have time to pursue my preference, for survival is the first priority". Whereas in U-B, one interviewee speaks frankly that "individual preference comes first when I need to make a decision" (U-B3), she thus chooses Finance as her second degree.

Numerically, the reference points of ability (10 in U-A and 9 in U-B) of the two universities are close. What is worth noting, however, is the different emphasis. In U-A, learners clearly express that their language ability is the most important consideration. Most of their concerns are rooted in their self-judgment during their attending agentive activities in the university, as demonstrated in the following quote:

Working as a trainee in companies made my language ability underexposed, I felt frustrated. After that, I struggle to improve my language. (U-A3)

The above quote illuminates that one agentive activity of being a trainee leads to comparison with non-English majors and self-reflection, which prods the interviewee into taking the other agentive activity, that is, the action of improving language ability. Correspondingly, in U-B, learners mainly lay stress on their mathematic ability. As expressed in the following quote:

My impaired ability in mathematic made me choose International Trade instead of Finance. (U-B6) Attaching importance to learners' mathematic ability is one of the key features of universities like U-B. 
Following this institutional focus, learners in U-B also stress their mathematic ability. Since mathematic ability has been cultivated from an early age, students' self-perception about this ability in the past years have impacted their choice of second degree major in university. Besides, all-round ability, including self-learning ability, ability to deal with a range of courses, etc. also occupies an important position when learners conduct agentive activities. As the following quote illustrates:

It is stressful to take too many courses in other majors. I am not strong enough to deal with stress. Besides, I think I can acquire those skills by myself. (U-B5)

The above quote demonstrates that the more courses learners attend, the more stressed they may feel. If learners are incapable of handling the stressful situation, they may choose to reduce the number of courses. Meanwhile, this quote also shows that the interviewee is not confident of his own self-learning ability, which leads him to give up attending courses in other majors and gaining a second/minor degree. All in all, learners' self-perception of their ability influences learners' choices of the interdisciplinary cultivation types and the majors of the second/minor degree.

Experience ( 8 in U-A and 9 in U-B) also makes a difference on both groups of learners, who mainly emphasize the impact of life experience and learning experience on their choices of being an English major, interdisciplinary courses and future employment. As the following two quotes show:

My father operates a foreign trade company. When I go to his office, I can hear him negotiating with foreigners. I find that what is used in negotiation is totally different from what we have learned in universities. What we learn about Business English in the classroom has little help to practice. (U-A2)

My father expects me to be a major in Economics. He thinks that there is a shortage of talents in the economic field. Hence, I choose Finance as my second degree. (U-B6)

The first quote elaborates that the life experience of having an access to family business impacts on interviewee's attitude towards the courses and the cultivation program she attends in university. In the second one, according to the interviewee's father, what China needs most is economic talents, the interviewee thus follows her father's advice to choose Economics as her second major. It reveals that parents' expectations, perceptions, or requirements influence learners' choices. Except for the life experience, in this subcategory, learners' learning experience also impacts learners' activities. As demonstrated in the following quotes:

The English training session I attended in my childhood laid a solid language foundation for me. So, I have had a strong interest in English since I was a child. (U-A3)

When I was in high school, I studied Economics by myself. Hence, I choose Economics as my second degree in university. (U-B4)

The first quote shows that the interviewee's English education she received in childhood influences her attitude towards English. The solid foundation of English makes her feel that learning English is not as difficult as other courses, she thus chooses English as her major in university. The second one shows that the interviewee's self-learning experience makes her interested in Economics. As long as there is an opportunity, she chooses Economics as her second degree without hesitation.

\subsubsection{Microgenetic Domain}

There is one subcategory in the microgenetic domain, i.e., the institutional factors, which refers to the effects of factors at the institutional level, and four spheres: university curriculum arrangements (the influence of institutional curriculum arrangements such as the course variety, the starting time of the interdisciplinary program, the interdisciplinary types, etc.); teaching content (the content of all the courses); teaching method (teachers' teaching methods in all the courses learners attended); and peer influence (the impact of the classmates, friends, etc.).

The influencing strength of the subcategory and spheres in both universities are presented in Table 4:

Table 4. Influencing strength of subcategory and spheres in the microgenetic domain

\begin{tabular}{llll}
\hline Subcategory & Spheres & Reference points (U-A) & Reference points (U-B) \\
\hline Institutional factors & & 57 & 52 \\
& University curriculum arrangements & 28 & 39 \\
& Teaching content & 12 & 5 \\
& Teaching method & 15 & 4 \\
& Peer influence & 2 & 4 \\
\hline
\end{tabular}


As Table 4 suggests, the reference points of institutional factors are 57 in U-A and 52 in U-B. After comparing the data from the two universities in this subcategory horizontally and vertically, the following aspects merit notice: First, in this subcategory, the strongest influencing factor in both universities is the university curriculum arrangements (28 in U-A and 39 in U-B), which is an important and somewhat difficult task for universities since it affects all learners in the whole institution, whereas learners' needs vary. The starting time of the interdisciplinary program is one of the main complaints in both universities. Learners in U-A hold the view that the starting time is too late, which brings about the negative consequence that what they learn in class is "too general and shallow to be taken as an advantage after graduation (U-A5)". Whereas learners in U-B express the opinion that the starting time is too early, because they need more time to enhance their language foundation when they begin their university study.

Besides, learners in U-A also complain that the curriculum arrangements place restrictions on their obtaining knowledge and attending social activities. The following quotes clarify this opinion:

There are too few directions and course options. What's more, if we want to take more courses than those required by the curriculum, extra fees are required. (U-A1)

The curriculum arrangements in the fourth year of our university impose restrictions on our attending activities to gain social experience. (U-A7)

The two quotes indicate that there are some problems with the institutional provisions. However, when confronted with these restrictions, instead of resisting or giving up, learners struggle to work out a compromise such as "to know the course arrangements of other majors through friends (U-A5)", "to audit (U-A5)", and "to negotiate and coordinate with internship units or teachers (U-A6)".

Except for those complaints, there are also some positive comments given mainly by learners in U-B. The main point is that they are provided with such a wide range of options and opportunities that they have adequate approaches to fulfill their own needs. The following quote can clarify this point:

Many options of courses and interdisciplinary types are offered, which are adequate for me. Those courses are very useful to let me know more about what I am interested in. (U-B6)

Secondly, the influencing strength of both teaching method (15 in U-A and 4 in U-B) and teaching content (12 in U-A and 5 in U-B) is much stronger in U-A than in U-B. In terms of the teaching method, learners in U-A deem that "teachers cannot make the course interesting and they just echo what the books say (U-A6)". Concerning the teaching content, learners in U-A mainly maintain that it is not professional enough, and some teachers lack practical experiences, which is an element that influences their learning experience and learning attitude greatly. Compared with those negative evaluations from U-A, comments from learners in U-B are more positive. They claim that "the teaching contents are very professional and helpful (U-B2)", and "the teaching methods are suitable (U-B1)".

Peers (2 in U-A and 4 in U-B) also have an influence on learners' choices. Several interviewees mention that they just follow their friends or classmates when they choose the direction courses, take examinations to gain certificates, or choose the major of minor/second degree, but the influence is not that salient in the present data.

\subsubsection{Summary}

Following the results presented above, the comparison result of the influencing strengths of the three categories is shown in Table 5.

Table 5. Influencing strengths of the three categories

\begin{tabular}{lll}
\hline Categories & Reference points (U-A) & Reference points (U-B) \\
\hline Cultural-historical domain & 33 & 26 \\
Ontogenetic domain & 25 & 45 \\
Microgenetic domain & 57 & 52 \\
\hline
\end{tabular}

From Table 5, it can be seen that, in both universities, the most powerful category is the microgenetic domain. In the case of the other two domains, in U-A, the influencing strength of the cultural-historical domain is stronger than the ontogenetic domain; in U-B, the opposite is true. 


\subsection{Discussion}

The empirical results have answered the research questions and proved the influence of various factors on learners' agentive activities, as well as presented the influencing strength of factors in different domains. The findings show that learner agency is impacted by multi-level sociocultural factors, as discussed by van Lier (2008) and Manyukhina and Wyse (2019), with diverse influencing strengths, which can be concluded as follows: in the cultural-historical domain, learners in U-A pay more attention to the local factors while learners in U-B lay more stress on the global factors; the national factors almost have an equal influence on learners in both universities, particularly, the labor market. In the ontogenetic domain, generally, learners in U-B pay more attention to their ontogenetic issues, especially their interests; learners in both universities emphasize individual ability, while the specific focus is different. Among the three categories, the influencing strength of the microgenetic domain is the strongest. In this domain, learners in both universities lay much emphasis on curriculum arrangements with different comments and focuses and learners in U-A also stress the impact of teachers, including teaching content and teaching method.

The different orientations of the two universities can explain those similarities and differences. As illustrated above, U-A is a regionally-oriented, provincial university of science and engineering under the local government; U-B is an internationally-oriented comprehensive university directly under the Ministry of Education. Firstly, different orientations lead to different development goals and different cultivation objectives, which can explain why learners stress different factors in the cultural-historical domain. No higher institution can "completely seal itself from global effects", but nevertheless not all of them "engage with each other to the same extent or intensity", the extent of globalization varies according to "policy, governance and management" (Marginson \& van der Wende, 2009, p. 20) as well as self-orientation. Echoing this statement, this study obtains a consistent result, that is, the global effects in U-B are stronger than in U-A. On one hand, the development goal of U-B is to be a world-class university. Globalization is on the institutional development agenda. Therefore, U-B may pay more attention to the global factors. However, as a university directly under the local government, the development goal of U-A is to be in the leading position of the newly established universities in the local province and to serve regional economic and social development as well as to train high-quality talents for the local. Thus, it may lay more emphasis on the local developments. It is reasonable for learners in U-A to stress the global elements and learners in U-B to focus more on local elements.

On the other hand, the cultivation objective in U-B is to cultivate learners equipped with "an international perspective". Learners in this university are expected to be potential leaders in fields they will be engaged in in the future. Following this objective, global elements are undoubtedly emphasized. However, the cultivation objective of U-A is to "train advanced application-orientated professionals with a solid foundation and profound knowledge in science and culture". In this cultivation program, global elements are not the main focuses. Following the cultivation objectives, what can be inferred is that the local elements are the focuses whereby learners in U-A pay more attention to the factor of the local environment.

Secondly, different orientations lead to the discrepancy in learners' language ability, which can explain why learners in different universities focus on different ontogenetic factors. It is a fact that the admission requirements of U-B are much higher than that of U-A. What can be inferred is that the language ability of most learners in U-B is higher than learners in U-A. However, the language proficiency requirements of the job market they will be confronted with in the future are the same. Consequently, learners in U-A may need to pay more attention to improving their language ability, and learners in U-B shift their focuses to other abilities which are required to obtain second/minor degrees or to meet their preferences. Additionally, what should be expected is that the overall quality and popularity of graduates from the two universities in the labor market may be different. As a result, learners' employment pressures in U-B are not as great as learners in U-A. Although learners in both universities emphasize the significance of the labor market, compared with interests, learners in U-B stress less on it. However, learners in U-A thus are not allowed to spend too much time pursuing individual interests, for they always emphasize the requirements of the society and future employment.

Furthermore, different orientations lead to differences in the resources available, which can explain why learners in both universities emphasize the significance of the institutional factors. In the era of globalization, the role of the nation in the educational system is not fading away, "the great majority of institutions continue to be nationally embedded and dependent on governmental legitimation and resource support" (Marginson \& van der Wende, 2009, p. 25), but nevertheless, the governmental resource support for each institution is unbalanced. There is a significant difference in the financial resources the two universities have access to. Generally, U-B can invest more in cultivating learners by offering more choices and cultivating high-quality teachers, who can provide more professional teaching content and are equipped with better teaching approaches. Then, what can be 
arrived at is that learners in U-B have more opportunities to fulfill their needs and development goals as well as individual preferences, whereas learners in U-A are somewhat restricted in enjoying those resources.

Moreover, different orientations lead to different expectations for learners. From the comments of learners in both universities, what can be inferred is that the teaching content of U-A is not as professional as that of U-B. In the curriculum of U-B, the aim is to cultivate learners with "an interdisciplinary professional background, and leadership competencies". To achieve the goal of cultivating potential leaders, universities and teachers may try to provide more professional courses to meet the requirements for leadership. However, learners U-A are expected to be "capable of working in the field of the practical English translation, international trade, foreign-oriented secretary and education". Thus, what they need is the practical knowledge that can be utilized to deal with this kind of work.

\section{Conclusions and Implications}

Employing a multi-site case study and adopting Dang and Marginson's (2013) framework, this study has examined the factors that have an influence on learners' agentive activities in two universities in the eastern part of China and presented the different influencing strength of those factors. Results have shown that agency is mediated by different levels of the sociocultural context and by the individual elements. Among all the factors, the most influential one manifests in the microgenetic domain, more specifically, the institutional context where learners situate. The influencing strength of specific subcategories and spheres varies due to the different orientations of the two universities.

This said, it has to be noted a limitation of this study and be advised to be cautious in interpreting the findings. This study was conducted on 14 learners in two universities in one eastern coastal city of China, so it would not be appropriate to make broad generalizations. More investigations into Chinese English majors' learning practice are essential to reveal the deeper nature of the relationship among English interdisciplinary talents development program, learning practice and learner agency and to propose policy adjustments. Meanwhile, the main data source of this study is the learner interview and questionnaire, what lacks is class observation and teacher interview, which can present to us a more comprehensive picture of learners' learning environment.

Meanwhile, learners have to balance new curricular demands and practical limitations. However, as this study has made clear, the efforts of individual learners are most effective when embedded in a context that augments their efforts. Language policy decisions at different levels, including content selections, curriculum arrangements, etc., will be most effective when learners' agency is facilitated. Especially recently the new curriculum requirement is to be implemented and expected to impact many English majors. This study indicates that in the process of implementing the national education policies and designing the corresponding institutional cultivation programs, due attention should be paid to the different orientations of universities and distinctive institutional features, thus promoting the development of universities and satisfying learners' needs better.

\section{References}

Ahearn, L. M. (2001). Language and agency. Annual Review of Anthropology, 30, 109-137. https://doi.org/10.1146/annurev.anthro.30.1.109

Baldauf, R. B. Jr. (2012). Introduction-language planning: Where have we been? Where might we be going? Revista Brasileira de Linguistica Aplicada, 12(2), 233-248. https://doi.org/10.1590/S1984-63982012000200002

Brown, J. (2015). Learner agency in language planning: A tripartite perspective. Language Problem \& Language Planning, 39(2), 171-186. https://doi.org/10.1075/lplp.39.2.04bro

Cross, R. A. (2009). Sociocultural framework for language policy and planning. Language Problems \& Language Planning, 33(1), 22-42. https://doi.org/10.1075/lplp.33.1.02cro

Dai, W. D. (2008). Report on the development of foreign language education in colleges and universities (1978-2008). Shanghai: Shanghai Foreign Language Education Press.

Dang, T. K. A., \& Marginson, S. (2013). Global learning through the lens of Vygotskian sociocultural theory. Critical Studies in Education, 54(2), 143-159. https://doi.org/10.1080/17508487.2012.722557

Dang, T. K. A., Nguyen, H. T. M., \& Le, T. T. T. (2013). The impact of globalization on EFL teachers' education through English as a medium of instruction: An example from Vietnam. Current Issues in Language Planning, 14(1), 52-72. https://doi.org/10.1080/14664208.2013.780321

Dang, T. M. A. (2012). Impact of globalization on ELT pre-service teacher education in a Vietnamese context: A sociocultural perspective. In C. Gitsaki \& R. B. Baldauf (Eds.), Future directions in applied linguistics: 
Local and global perspectives (pp. 140-157). Cambridge, CA: Cambridge Scholars.

Fenton-Smith, B., \& Gurney, L. (2016). Actors and agency in academic language policy and planning. Current Issues in Language Planning, 17(1), 72-87. https://doi.org/10.1080/14664208.2016.1115323

Finardi, K. R., \& Guimarães, F. F. (2021). Local agency in national language policies: The internationalisation of higher education in a Brazilian institution. Current Issues in Language Planning, 22(1-2), 157-179. https://doi.org/10.1080/14664208.2019.1697557

Hamid, M. O., \& Baldauf, R. B. Jr. (2014). Public-private domain distinction as an aspect of LPP frameworks: A case study of Bangladesh. Language Problems \& Language Planning, 38(2), 912-210. https://doi.org/10.1075/lplp.38.2.05ham

Hu, K. B. (2010). Training English majors with two or more specialized expertises, innovative consciousness and international vision: Theoretic consideration and practice. Foreign Language in China, 6, 8-16.

Lantolf, J. P., \& Pavlenko, A. (2001). Second language activity theory: Understanding second language learners as people. In M. P. Breen (Ed.), Learner contributions to language learning: New directions in research (pp. 141-158). Harlow: Pearson Education.

Li, C. S., \& Xu, B. F. (2006). A history of modern foreign language education in China. Shanghai: Shanghai Foreign Language Education Press.

Liddicoat, A. J., \& Taylor-Leech, K. (2021). Agency in language planning and policy. Current Issues in Language Planning, 22(1-2), 1-18. https://doi.org/10.1080/14664208.2020.1791533

Liu, Y., \& Li, Z. W. (2014). Needs survey and analysis of post-90s English majors' learning. Foreign Language Research, 3, 47-51.

Manyukhina, Y., \& Wyse, D. (2019). Learner agency and the curriculum: A critical realist perspective. The Curriculum Journal, 30(3), 223-243. https://doi.org/10.1080/09585176.2019.1599973

Marginson, S., \& Rhoades, G. (2002). Beyond national states, markets, and systems of higher education: A glonacal agency heuristic. Higher Education, 43, 281-309. https://doi.org/10.1023/A:1014699605875

Marginson, S., \& van der Wende, M. (2009). The new global landscape of nations and institutions. In Organization for economic cooperation and development higher education to 2030 (Volume 2: Globalisation, pp. 17-62). Paris: OECD. https://doi.org/10.1787/9789264075375-en

Phan, H., \& Hamid, M. O. (2017). Learner autonomy in foreign language policies in Vietnamese universities: An exploration of teacher agency from a sociocultural perspective. Current Issues in Language Planning, 18(1), 39-56. https://doi.org/10.1080/14664208.2016.1201231

Siekmann, S., \& Charles, W. (2011). Upingakuneng (When they are ready): Dynamic assessment in a third semester Yugtun class. Assessment in Education: Principles, Policy and Practice, 18(2), 151-168. https://doi.org/10.1080/0969594X.2011.565463

van Lier, L. (2008). Agency in the classroom. In J. P. Lantolf \& M. E. Poehner (Eds.), Sociocultural theory and the teaching of second language (pp. 163-186). London, England: Equinox.

Vennela, R., \& Kandharaja, K. M. C. (2021). Agentive responses: A study of students' language attitudes towards the use of English in India. Current Issues in Language Planning, 22(1-2), 243-263. https://doi.org/10.1080/14664208.2020.1744319

Vygotsky, L. S. (1978). Interaction between learning and development. Readings on the Development of Children, 23(3), 34-41.

Vygotsky, L. S. (1981a). The instrumental method in psychology. In J. V. Wertsch (Ed.), The concept of activity in Soviet psychology (pp. 134-143). New York: M.E. Sharpe.

Vygotsky, L. S. (1981b). The genesis of higher mental functions. In J. V. Wertsch (Ed.), The concept of activity in Soviet psychology (pp. 144-188). New York: Sharpe.

Wang, G. M., She, W. J., \& Song, J. J. (2014). The psychological structures model of highly effective mathematics learning based on the NVivo10 qualitative analysis. Studies of Psychology and Behavior, 12(1), $74-79$.

Yang, Z. (2007). Training skills and developing intelligence: Integrating instrumentality and humanity in foreign language education. Foreign Language Research, 6, 133-137. 
Zhang, Y. (2012). The educational reform on the basis of the New Syllabus. Journal of Jimei University, 13(3), 92-96.

Zhao, S. H., \& Baldauf, R. B. Jr. (2012). Individual agency in language planning Chinese script reform as a case study. Language Problems \& Language Planning, 36(1), 1-24. https://doi.org/10.1075/lplp.36.1.01zha

Zhong, M. S. (2006). Deepening the reform of foreign language education with the concept of elite education-undergraduate teaching reform of Beijing Foreign Studies University. Foreign Language Teaching and Research, 38(5), 254-256.

\section{Copyrights}

Copyright for this article is retained by the author, with first publication rights granted to the journal.

This is an open-access article distributed under the terms and conditions of the Creative Commons Attribution license (http://creativecommons.org/licenses/by/4.0/). 